\title{
PART V
}

\section{REPORTS ON SPECIAL OBSERVATIONS}




\title{
TEMPORAL OBSERVATIONS OF THE $\lambda 5303$ EMISSION LINE
} PROFILE DURING THE 74 MINUTE TOTALITY FROM THE CONCORDE SST AT THE 30 JUNE 1973 TOTAL SOLAR

\author{
ECLIPSE: PRELIMINARY INTENSITY VARIATIONS
}

\author{
ABOVE AN ACTIVE REGION*
}

D. H. LIEBENBERG and M. M. HOFFMAN

University of California, Los Alamos Scientific Laboratory, Los Alamos, N.M., U.S.A.

\begin{abstract}
Nature). Apparatus was flown aboard the French-British Concorde SST to obtain high resolution emission line intensity profiles during the 30 June 1973 total solar eclipse. A prime objective was to obtain profiles that could be used to determine the presence in the Fe XIV coronal emission line, $530.3 \mathrm{~nm}$, of the $300 \mathrm{~s}$ periodicity such as is observed in the photosphere and chromosphere. The long totality duration of $74 \mathrm{~min}$ on the French Concorde 001 provided a unique opportunity for this study. At the $55000 \mathrm{ft}$ cruise altitude weather influences are negligible, scattered light background reduced and seeing conditions excellent. The instrumentation included a high resolution pressure scanned Fabry-Perot interferometer and high resolution recordind. This instrumentation was perfected in earlier Los Alamos Scientific Laboratory solar eclipse flights since 1965 (Liebenberg, 1965, 1967; Hoffman et al., 1970). A $12 \mathrm{~cm}$ aperture window and $7.7 \mathrm{~cm}$ aperture $f / 13$ telescope were designed to optimize the use of the available space as shown in Figure 1.

Results were obtained in a preliminary analysis by determining the emission line peak intensity for a single location in the solar corona near the base of a helmet structure above the NW limb. Averages over one minute intervals are shown in Figure 2 for a 15 min section of the recording. Background intensity of 0.05 on the arbitrary intensity scale has been subtracted from each average. A shift in time base by $t_{0}+30 \mathrm{~s}$ was performed to determine whether the large statistical noise might cause the average over a one minute interval to change. As is seen the $6 \pm 1$ min periodicity of the $530.3 \mathrm{~nm}$ peak intensity is plainly observed at a level of 2 standard deviations. Further analysis should determine whether this is a progressive wave motion and the extent to which the line profile itself is modified in correlation with the intensity fluctuations.

Earlier observations (Noxon, 1966; Morel, 1972) have been inconclusive in showing an intensity fluctuation in $\mathrm{Fe}$ XIV line emission. The present data are completely free of the influence of the Fraunhofer absorption line introduced in scattered light to coronagraphic observations. Measurements in X-ray lines have shown a similar intensity periodicity with which the present preliminary results in Fe XIV line emission agree (Chapman et al., 1972).
\end{abstract}

* Work performed under the auspices of the U.S. Atomic Energy Commission.

Gordon Newkirk, Jr. (ed.), Coronal Disturbances, 485-487. All Rights Reserved Copyright (C) 1974 by the IAU. 


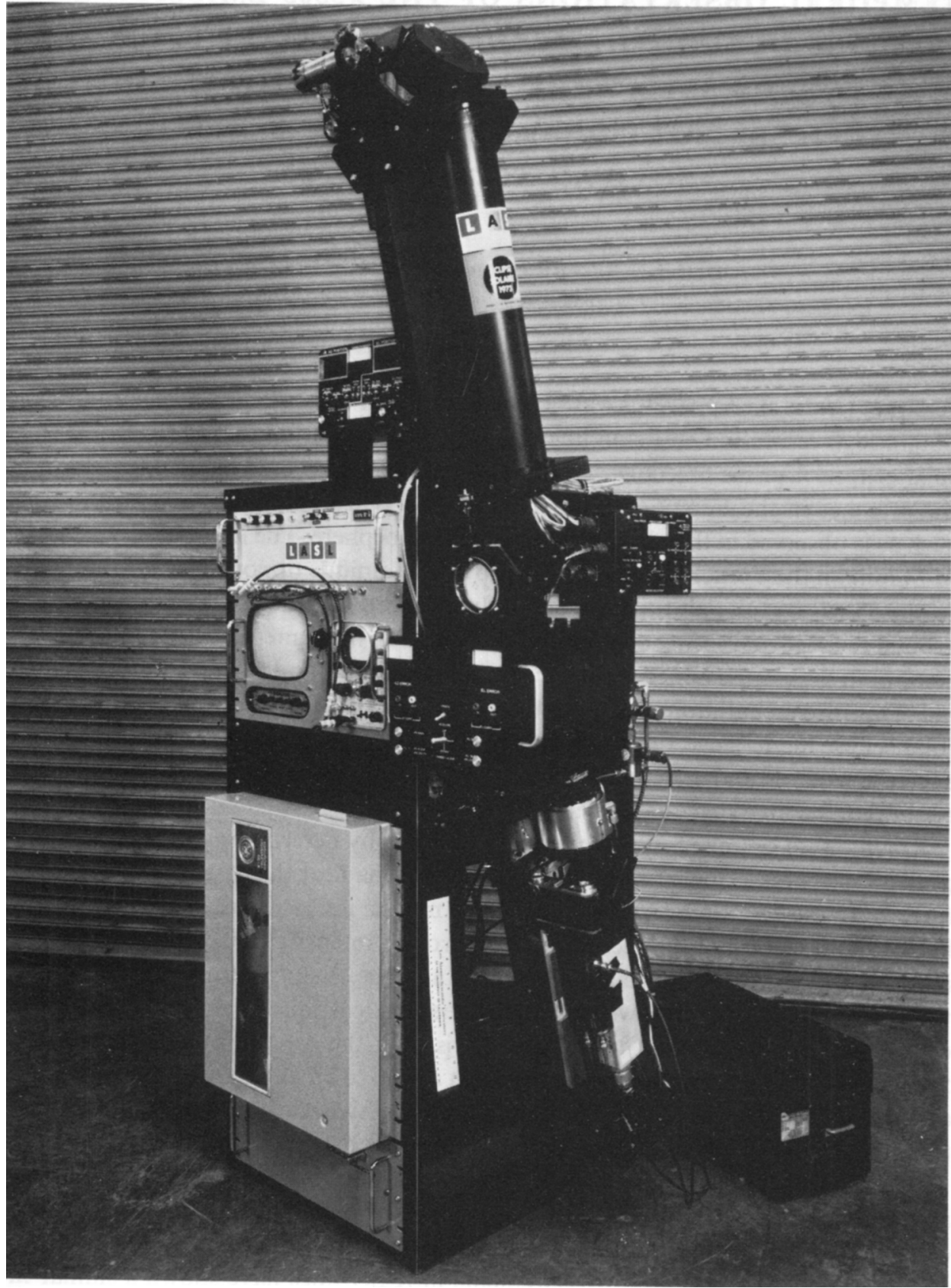

Fig. 1. The Los Alamos apparatus as installed on the Concorde SST. The optical train cover is removed to show the Fabry-Perot interferometer cell and the image intensified vidicon camera. Video data monitoring and recording equipment and image guidance controls are arranged so that one person can operate the equipment. 


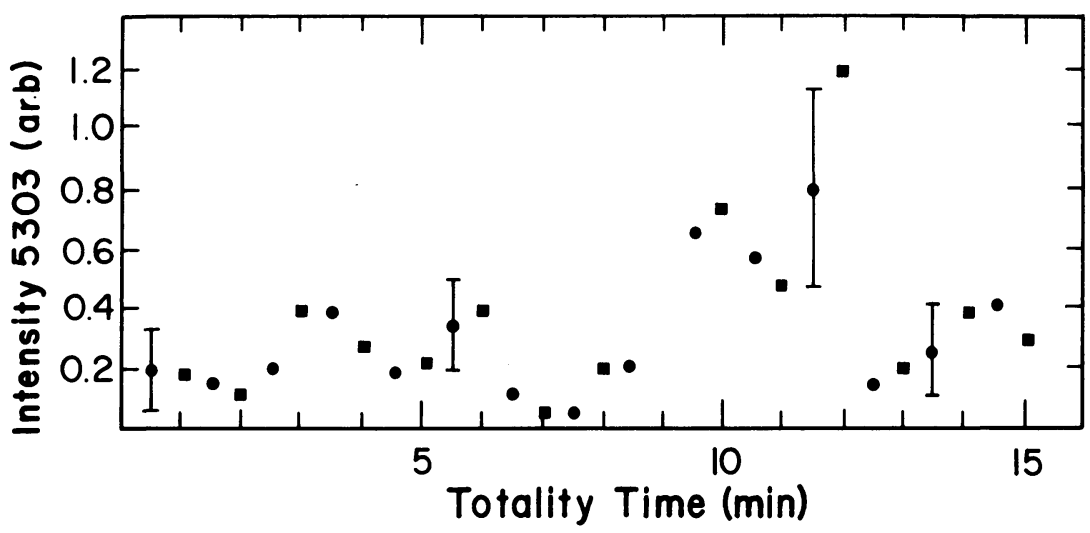

Fig. 2. Peak intensity of $\lambda 5303$ in arbitrary units vs time during totality. The points are averages over one minute intervals and $\square$ are the same with a shift in time base $t_{0}$ to $t_{0}+30 \mathrm{~s}$ as discussed in the text. Standard deviations are shown for a few points and are typical for all points.

\section{Acknowledgements}

We thank Mr R. Lang, Mr Ed Brown, M. Sanders, J. Calligan and Dr A. Cox of LASL for help with equipment and flight plans required for these observations. To the chief test pilot $\mathbf{M}$. André Turcat, Aerospatiale, and scientific coordinator Dr P. Charvin, Institute de Astronomie et du Géophysique, we are indebted for a successful Concorde flight. Financial support was provided by U.S. Atomic Energy Commission through LASL, U.S. National Science Foundation Grant AG-433 and the Delegation General for Scientific and Technical Research of France.

\section{References}

Chapman, R. D., Jordan, S. D., Neupert, W. M., and Thomas, R. J. : 1972, Astrophys. J. 174, L97.

Hoffman, M. M., Brown, E., and Liebenberg, D. H.: 1970, Am. Astron. Soc., June 1970.

Liebenberg, D. H.: 1965, Proc. NASA Solar Eclipse Symposium, Dec. 1965.

Liebenberg, D. H.: 1967, Astron. J. 72, 307.

Morel, C.: 1972, 'Detection of Waves in the Solar Corona', M. S. Thesis, Univ. Colorado.

Noxon, J. F.: 1966, Astrophys. J. 145, 400.

\section{DISCUSSION}

Schmidt: Do you plan to evaluate your results to find propagation effects from time-distance correlations? Liebenberg: We have reasonably complete data around limb and extending to nearly $2 R_{\odot}$. In addition to intensity measurements, full line profiles were obtained and will be used in the more complete analysis.

Brandt: H. R. Chapman, S. Jordan, W. Neupert, and R. Thomas have observed line intensity variations with the OSO-7 spectrometer experiment. The EUV lines studied refer to a variety of excitation conditions which cover the chromosphere, transition zone, and the lower corona. In all cases, a power spectrum analysis showed intensity oscillations with periods of approximately $300 \mathrm{~s}$. Thus, these oscillations extend at least to the altitude of the lower corona.

Athay: Did the window temperature cause any problems?

Liebenberg: The skin temperature was $128^{\circ} \mathrm{C}$ (hence no consideration problems). Our experiment could not be affected. 